Chemosphere, Volume 81, Issue 11, December 2010, Pages 1454-1462

\title{
Multimedia fate of petroleum hydrocarbons in the soil : oil matrix of constructed biopiles
}

Frédéric Coulon ${ }^{a^{*}}$, Michael J. Whelan ${ }^{a}$, Graeme I. Paton ${ }^{b}$, Kirk T. Semple ${ }^{c}$, Raffaella Villa ${ }^{a}$ and Simon J.T. Pollard ${ }^{a}$

${ }^{a}$ Cranfield University, Sustainable Systems Department, School of Applied Sciences, Cranfield, MK43 0AL, UK.

${ }^{b}$ University of Aberdeen, Institute of Biological and Environment Science, Cruickshank Building, Aberdeen, AB24 3UU, UK

${ }^{c}$ Lancaster University, Lancaster Environment Centre, Lancaster, LA1 4YQ, UK

Coulon Frédéric and Whelan J Michael contributed equally to this work

*Corresponding author: Email: f.coulon@ cranfield.ac.uk Tel: +44 (0)1234 750 111; Fax: +44 (0)1234 751671 


\section{ABSTRACT}

A dynamic multimedia fugacity model was used to evaluate the partitioning and fate of petroleum hydrocarbon fractions and aromatic indicator compounds within the soil : oil matrix of three biopiles. Each biopile was characterised by four compartments: air, water, soil solids and non-aqueous phase liquid (NAPL). Equilibrium partitioning in biopile A and B suggested that most fractions reside in the NAPL, with the exception of the aromatic fraction with an equivalent carbon number from 5 to $7\left(\mathrm{EC}_{5-7}\right)$. In Biopile $\mathrm{C}$, which had a higher soil organic carbon content (13\%), the soil solid phase was the most important compartment for the light aliphatic fractions $\left(\mathrm{EC}_{5-6}\right.$ and $\left.\mathrm{EC}_{6-8}\right)$ and most of the aromatic fractions with the exception of the $\mathrm{EC}_{16-21}$ and $\mathrm{EC}_{21-35}$. Although there is significant uncertainty about the rate of biodegradation in NAPL phase, our starting hypothesis was that hydrocarbons do not degrade within the NAPL phase. This was supported by the good agreement between predicted and measured hydrocarbon concentrations in Biopile B when the degradation rate constant in NAPL was set to zero. In all scenarios, biodegradation in the soil was predicted as the dominant removal process for all fractions, except for the aliphatic $\mathrm{EC}_{5-6}$ which was lost predominantly via volatilisation. Although neglecting an explicit NAPL phase in the model yielded a similar prediction of total petroleum hydrocarbon (TPH) behaviour, the predicted concentrations in the air and water phases were significantly increased with consequent changes in potential mobility. Further comparisons between predictions and measured data, particularly concentrations in the soil mobile phases, are required to ascertain the true value of including an explicit NAPL phase in models of this kind.

Keywords: oil, petroleum hydrocarbon fractions, indicator compounds, modelling, fate 


\section{Introduction}

Petroleum hydrocarbons are common environmental contaminants and represent a complex mixture of aliphatic and aromatic compounds with minor amounts of heterocyclic compounds containing nitrogen, sulphur and oxygen (Farewell-Jones, 2003; Howard et al., 2005). Once released into the environment, most of the lower-molecular weight petroleum hydrocarbon compounds are subject to volatilization, oxidation, dissolution and biotransformation processes (Pollard et al., 1994; Howard et al., 2005). In contrast, the heavier compounds (boiling points $c a .300->600{ }^{\circ} \mathrm{C}$ and carbon number ranges $>\mathrm{C}_{20}$ ) are desorbed slowly into the aqueous phase of the oil-soil matrix due to their low water solubility, low vapour pressure and high octanol water partition coefficients $\left(\mathrm{K}_{O W}\right)$ (Pollard et al., 1994; Huesemann et al., 2004).

Many hydrocarbon contaminants have sufficiently similar intrinsic physicochemical properties that they can be classed into groups or fractions when considering fate and transport behaviour as well as toxicity (Twerdok, 1999; Howard et al., 2005; Foster et al., 2005). In view of this, many jurisdictions encourage a combined indicator and fractionation approach for TPH analysis, separating aliphatic and aromatic substances using carbon number ranges as these are known to differ in their toxicity, solubility and fate and transport characteristics (Weisman, 1998; Brown et al., 1999; Brassington et al., 2007). TPH risk assessment frameworks and criteria have been developed by, among others, Canada, the United States of America, Australia, New Zealand and the United Kingdom (Brassington et al., 2007). However, these frameworks and the exposure assessments embedded within them do not explicitly address the partitioning of hydrocarbon fractions and indicator compounds within the soil-oil matrix of contaminated soils. This may contribute to an overestimation of both the ecotoxicological effects of the fractions and their mobility in air and water leading to an overestimation of health effects associated with these compounds. 
The authors have maintained a long-standing research interest in the characterisation of heavy oil wastes (Pollard et al., 1992; 1994; Risdon et al., 2008) and the representativeness of fate and exposure models for hydrocarbon-contaminated soils (Zemanek et al., 1997; Semple et al., 2003). At hydrocarbon-contaminated sites, the oil is clearly the source term for riskcritical contaminants. Refractory and residual TPH (residual NAPL lodged between soil particles and resistant to onward biotransformation) is a free oil phase, often retaining a greater affinity than SOM for hydrophobic organics (Huesemann et al., 2004; Semple et al., 2004). It is frequently the principal source of organic carcinogens or suspected carcinogens (e.g. benzo $[a]$ pyrene, benz $[a]$ anthracene) that drive quantitative risk assessments at contaminated sites (Weisman, 1998; Brown et al., 1999; Brassington et al., 2007). Previous work on the qualitative understanding of oil phase partitioning and co-solvency (Pollard et al., 1994; Zemanek et al., 1997) has shown that the role of residual NAPL in exposure assessment is often underestimated (especially at sites contaminated with heavy oil) and that petroleum hydrocarbon mobility may sometimes be over-estimated.

Application of fugacity models (Mackay and Paterson, 1991; Mackay, 2001) for predicting the phase distribution and concentrations of organic contaminants during treatment (Pollard et al., 2008; Coulon et al., 2009) is now proving valuable for informing exposure assessments (hazard and risk) and the optimization of in-situ remediation. However, such models have yet to be applied to both petroleum hydrocarbon fractions and risk indicator compounds. In addition, the NAPL phase within biopile systems has been largely ignored (McKone, 1996; Walter et al., 2000; Pollard et al, 2008).

Constructed biopiles consist of above ground heaps or cells of contaminated soils within which aerobic microbial activity is stimulated via water and nutrient addition along with aeration (Batelle, 1996; Mohn et al., 2001). Addition of water is often important for successful biopile operation, particularly in arid areas where aeration can enhance water 
evaporation and reduce pile moisture content to levels which limit degradation rates. Biopiles are typically constructed on an impermeable base to reduce the potential migration of leachate to the subsurface environment. A perforated pipe network, installed above the base, is connected to a blower that facilitates aeration of the pile (Battelle, 1996; Mohn et al., 2001; Pollard et al., 2008). In some cases, a leachate collection system is constructed, especially if water and nutrients are added to the pile. The piles are generally covered with an impermeable membrane to prevent the release of contaminants and/or contaminated soil to the environment and to protect the soil from wind and precipitation. Biopiles operate effectively in temperate climates but can also be used in colder climates if warm air is introduced through the aeration process (Mohn et al., 2001).

In this study, we explored hydrocarbon behaviour in three biopile systems, using a bespoke multimedia fugacity model which explicitly included a NAPL phase. Multiphase partitioning of the aliphatic and aromatic fractions, as well as eleven aromatic indicator compounds, were modelled within the soil-oil matrix of each biopile. Our research aims were (i) to evaluate the implications of an explicit consideration of partitioning and degradation in NAPL on the predicted patterns hydrocarbon behaviour; (ii) to compare how well indicator compounds represent different hydrocarbon fractions; and (iii) to explore the extent to which effective treatment times could be estimated using a dynamic fugacity model.

\section{Materials and Methods}

\section{Biopile characteristics and volumetric composition}

Three soils contaminated with petroleum hydrocarbons were used to develop three biopile systems (A, B and C), as previously described by Pollard et al. (2008). Briefly, each biopile had a volume of $624 \mathrm{~m}^{3}$ and a mass of $c a .750$ tonnes. The material in the biopile was treated as four environmental compartments: air, water, soil solids (with associated organic carbon 
fraction) and NAPL (Table 1). The concentration of NAPL was assumed to be equal to the measured concentration of TPH (Park and Juan, 2000). Note that although the total volume of each biopile soil was the same, their composition differed. Of particular significance was the much higher soil organic carbon concentration of Biopile C (13\%) compared with Biopiles B (6\%) and A (5\%). The moisture content of the soil in Biopile C (34\%) was also much higher than in soil A (15\%) and B (21\%) and the bulk density was lower. It should also be noted that although the TPH concentration in the three biopiles considered was relatively low, suggesting that the oil may be present mainly as oil-coated soil solids, heavily contaminated soils are likely to contain discrete oil-filled soil pores. Since many hydrophobic contaminants have a greater affinity for the NAPL phase rather than for soil organic matter, an explicit NAPL compartment was therefore included in the model rather than representing the oil via an increase in soil organic matter content.

\section{Hydrocarbon analysis}

TPH extraction procedure and gas chromatography-mass spectrometry analysis were carried out as previously described by Risdon et al. (2008). Briefly, soil samples (5 g) were chemically dried with $5 \mathrm{~g}$ of anhydrous sodium sulphate and then extracted using a sequential ultrasonic acetone/hexane (1:1) solvent extraction. Hydrocarbon fractions and indicator compounds were identified and quantified using a Perkin Elmer AutoSystem XL gas chromatograph coupled to a Turbomass Gold mass spectrometer operated at $70 \mathrm{eV}$ in positive ion mode. The mass spectrometer was operated in full scan mode (range m/z 50-500) for quantitative analysis of target alkanes and polycyclic aromatic hydrocarbons (PAH). External multilevel calibrations were carried out for both aliphatic and aromatic fractions with quantification ranging from 0.5 to $2500 \mu \mathrm{g} \mathrm{mL}^{-1}$ and from 1 to $5 \mu \mathrm{g} \mathrm{mL}^{-1}$, respectively. Deuterated alkanes $\left(\mathrm{C}_{10}{ }^{\mathrm{d} 22}, \mathrm{C}_{19}{ }^{\mathrm{d} 40}\right.$ and $\left.\mathrm{C}_{30}{ }^{\mathrm{d} 62}\right)$ and deuterated PAHs (naphthalene ${ }^{\mathrm{d} 8}$, 
Table 1: Dimensions and characteristics of each biopile

\begin{tabular}{|c|c|c|c|c|c|}
\hline & \multicolumn{2}{|c|}{ Biopile characteristics } & Biopile A & Biopile B & Biopile C \\
\hline & \multicolumn{2}{|l|}{$\mathrm{V}_{\mathrm{A}}\left(\mathrm{m}^{3}\right)$} & 310 & 337 & 399 \\
\hline & \multicolumn{2}{|l|}{$\mathrm{V}_{\mathrm{W}}\left(\mathrm{m}^{3}\right)$} & 91 & 108 & 122 \\
\hline & \multicolumn{2}{|l|}{$V_{S}\left(m^{3}\right)$} & 209 & 162 & 96 \\
\hline & \multicolumn{2}{|c|}{$\mathrm{V}_{\mathrm{NAPL}}\left(\mathrm{m}^{3}\right)$} & 14 & 17 & 7 \\
\hline & \multicolumn{2}{|c|}{ Total volume $\left(\mathrm{m}^{3}\right)$} & 624 & 624 & 624 \\
\hline & \multicolumn{2}{|c|}{$\%$ Total org $\mathrm{C}$} & 7 & 9 & 15 \\
\hline & \multicolumn{2}{|c|}{$\%$ org $\mathrm{C}$ in soil phase } & 4.92 & 6.04 & 13.17 \\
\hline & \multicolumn{2}{|c|}{ Soil density $\left(\mathrm{kg} \mathrm{m}^{-3}\right)$} & 2400 & 2400 & 2400 \\
\hline & \multicolumn{2}{|c|}{ Bulk density $\left(\mathrm{kg} \mathrm{m}^{-3}\right)$} & 973 & 823 & 576 \\
\hline & \multicolumn{2}{|c|}{$\mathrm{TPH}\left(\mathrm{mg} \mathrm{kg}^{-1}\right)$} & 20848 & 29555 & 18285 \\
\hline & \multicolumn{2}{|c|}{$\sum$ Aliphatic hydrocarbons $\left(\mathrm{mg} \mathrm{kg}^{-1}\right)$} & 15092 & 19869 & 7271 \\
\hline & \multicolumn{2}{|c|}{$\sum$ Aromatic hydrocarbons $\left(\mathrm{mg} \mathrm{kg}^{-1}\right)$} & 5756 & 9686 & 11014 \\
\hline & \multicolumn{5}{|c|}{ Mass in the system (kg) } \\
\hline \multirow{6}{*}{ 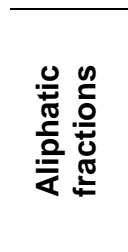 } & \multicolumn{2}{|l|}{$\mathrm{EC}_{5-6}$} & $\mathrm{nd}^{\mathrm{a}}$ & 3 & 0.02 \\
\hline & \multicolumn{2}{|l|}{$\mathrm{EC}_{>6-8}$} & 2 & 18 & 0.5 \\
\hline & \multicolumn{2}{|l|}{$\mathrm{EC}_{>} 8-10$} & 5 & 26 & 2 \\
\hline & \multicolumn{2}{|l|}{$\mathrm{EC}>10-12$} & 70 & 470 & 225 \\
\hline & \multicolumn{2}{|l|}{$\mathrm{EC}>12-16$} & 6679 & 7502 & 1574 \\
\hline & \multicolumn{2}{|l|}{$\mathrm{EC}>16-35$} & 2407 & 2186 & 812 \\
\hline & \multicolumn{2}{|l|}{$\mathrm{EC}_{5-7}$} & nd & 0.6 & 0.4 \\
\hline & \multicolumn{2}{|l|}{$\mathrm{EC}_{>7-8}$} & nd & 3 & 1 \\
\hline & \multicolumn{2}{|l|}{$\mathrm{EC}_{>} 8-10$} & 4 & 12 & 8 \\
\hline 호 & \multicolumn{2}{|l|}{$\mathrm{EC}>10-12$} & 16 & 44 & 21 \\
\hline 인 & \multicolumn{2}{|l|}{$\mathrm{EC}_{>12-16}$} & 588 & 821 & 647 \\
\hline & \multicolumn{2}{|l|}{$\mathrm{EC}>16-21$} & 1606 & 2195 & 1365 \\
\hline & $\mathrm{EC}_{>21-35}$ & & 1281 & 1899 & 1917 \\
\hline & $\mathrm{EC}_{>10-12}$ & Naphthalene & 11 & 22 & 17 \\
\hline & & Acenaphthene & 11 & 13 & 10 \\
\hline ᄒᄒ & $E C>12-16$ & 1-Methylnaphthalene & 15 & 19 & 16 \\
\hline$\widetilde{\mathscr{J}} . \subseteq$ & & Phenanthrene & 29 & 33 & 31 \\
\hline 을 至 용. & $E C>16-21$ & Pyrene & 5 & 6 & 5 \\
\hline.$\frac{5}{0} \sum_{0}^{3} \frac{0}{0}$ & & Fluoranthene & 6 & 7 & 6 \\
\hline 歾 & & Benzo $[a]$ pyrene & 3 & 5 & 3 \\
\hline ह้ จั & & Benzo $[b]$ fluoranthene & 3 & 3 & 3 \\
\hline 원 을 & $\mathrm{EC}>21-35$ & Benzo $[k]$ fluoranthene & 3 & 3 & 2 \\
\hline ర్ & & Chrysene & 2 & 3 & 2 \\
\hline & 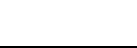 & Dibenzo $[a, h]$ anthracene & 1 & 2 & 1 \\
\hline
\end{tabular}
(oil) 
phenanthrene $^{\mathrm{d} 10}$, chrysened ${ }^{12}$ and perylene ${ }^{\mathrm{d} 12}$ ) were added as internal standards at

concentrations of 5 and $2 \mu \mathrm{g} \mathrm{mL}{ }^{-1}$, respectively. For quality control, a $500 \mu \mathrm{g} \mathrm{mL}^{-1}$ diesel standard and mineral oil were analyzed every 10 samples. Concentration and mass in each biopile system are reported in Table 1.

\section{Compilation of property data for hydrocarbon fractions and indicators}

Petroleum hydrocarbon fractions and indicator compounds used in this study are shown in Tables 2 and 3, respectively. Each fraction is further divided based on its equivalent carbon number (ECn), which is either related to the boiling point (b.p.) normalized to the b.p. of the n-alkanes, or determined via the retention time of the compounds in a b.p. gas chromatography column (Twerdok, 1999). This approach has been recognized as a more appropriate differentiation technique than the actual carbon number of the chemical (Brown et al., 1999; Twerdok, 1999). For hydrocarbons with higher relative carbon number indices, the disparity (in terms of EC) between aliphatic and aromatic hydrocarbons is substantial (Brassington et al., 2007). Each hydrocarbon subset is considered to contain compounds with similar properties (Foster et al., 2005; Howard et al., 2005). The values of the physicochemical properties of the aliphatic and aromatic compounds constituting each hydrocarbon fraction were compiled from Røenningsen et al. (1989), TPHCWG (1999), Mackay (2001), Foster et al. (2005) and Nathanail et al. (2007). Biodegradation half-lives for each hydrocarbon compound were estimated for air, water and soil using the Estimation Program Interface (EPI) Suite ${ }^{\mathrm{TM}}$ for Microsoft ${ }^{\circledR}$ Windows (version 3.10) (Syracuse Research Corp., http://www.syrres.com/esc/est_soft.htm).

Biodegradation half-lives in NAPL are rarely, if ever, measured or predicted. Therefore five scenarios were developed concerning the presence of an explicit NAPL compartment and the degradation of hydrocarbons within it. Our starting hypothesis was that petroleum 
hydrocarbons will have infinite degradation half-lives in an explicit NAPL compartment (Scenario 1: NAPL-No deg) owing to factors such as toxicity to microorganisms, lack of water, nutrients and oxygen to support degradation. In Scenario 2 (NAPL - Deg half rate) half-lives in NAPL were assumed to be half of those assumed for the bulk soil. In Scenario 3 (NAPL-Deg), half-lives in NAPL were assumed to be equal to the respective half-lives predicted for the bulk soil. In Scenario 4 (No NAPL - Enhanced SOC), no explicit NAPL compartment was considered but the presence of an oil residue was captured via an increase in the organic carbon content (to 7, 9 and $15 \%$ respectively for Biopiles A, B, and C). In Scenario 5 (No NAPL), no explicit NAPL compartment was considered and soil organic carbon content was not augmented to account for the presence of an oil residue.

To obtain half-lives for each hydrocarbon fraction which adequately represent all hydrocarbon components, a subset of hydrocarbons were selected for each structural class and carbon number. These are given in the Supporting Information. Representative hydrocarbons were selected on the basis of molecular structure, relative volumetric composition in crude oil and property data availability. The overall half-lives $\left(T_{O}\right)$ were calculated as

$$
T_{O}=\frac{\ln (2)}{\sum_{i=1}^{N} w_{i} \cdot k_{i}}
$$

where $w_{i}$ and $k_{i}$ are, respectively, the mass fraction and first order kinetic rate constant of individual component $i$, and $N$ is the number of representative components within each group. 
Table 2: Physicochemical characteristics of the aliphatic and aromatic fractions and their biodegradation half lives in air, water and bulk soil.

\begin{tabular}{|c|c|c|c|c|c|c|c|c|c|c|}
\hline $\begin{array}{l}\text { Petroleum } \\
\text { hydrocarbon } \\
\text { fractions }\end{array}$ & $\begin{array}{l}\text { Molecular } \\
\text { weight } \\
\left(\mathrm{g} \mathrm{mol}^{-1}\right)\end{array}$ & $\begin{array}{c}\text { Water } \\
\text { solubility } \\
\left(\mathrm{mg} \mathrm{L}^{-1}\right)\end{array}$ & $\begin{array}{c}\text { Vapour } \\
\text { pressure }(\mathrm{Pa}) \\
\text { at } 10{ }^{\circ} \mathrm{C}\end{array}$ & $\begin{array}{l}\text { Henry's Law } \\
\text { constant }^{\mathrm{a}} \\
\left(\mathrm{Pa} \mathrm{m}^{3} \mathrm{~mol}^{-1}\right)\end{array}$ & $\begin{array}{l}\mathrm{Log} \\
\mathrm{K}_{\mathrm{OW}}\end{array}$ & $\begin{array}{l}\text { Log } \\
\mathrm{K}_{\mathrm{OC}}\end{array}$ & $\begin{array}{c}\text { Density } \\
\left(\mathrm{kg} \mathrm{m}^{-3}\right)\end{array}$ & $\begin{array}{l}\text { Half life } \\
\text { in air }^{c} \\
\text { (h) }\end{array}$ & $\begin{array}{l}\text { Half life } \\
\text { in water }^{c} \\
\text { (h) }\end{array}$ & $\begin{array}{c}\text { Half life } \\
\text { in soil }^{\mathrm{c}} \\
\text { (h) }\end{array}$ \\
\hline \multicolumn{11}{|l|}{ Aliphatic } \\
\hline $\mathrm{EC}_{5-6}$ & 81 & $3.60 \mathrm{E}+01$ & $3.54 \mathrm{E}+04$ & $8.18 \mathrm{E}+04$ & 3.30 & 2.90 & 668 & 46 & 252 & 505 \\
\hline $\mathrm{EC}_{>6-8}$ & 100 & $5.40 \mathrm{E}+00$ & $6.37 \mathrm{E}+03$ & $1.24 \mathrm{E}+05$ & 4.10 & 3.60 & 721 & 35 & 262 & 524 \\
\hline $\mathrm{EC}_{>8-10}$ & 130 & 4.30E-01 & $6.37 \mathrm{E}+02$ & $1.99 \mathrm{E}+05$ & 5.20 & 4.50 & 749 & 25 & 215 & 430 \\
\hline $\mathrm{EC}_{>10-12}$ & 160 & $3.40 \mathrm{E}-02$ & $6.39 \mathrm{E}+01$ & $2.97 \mathrm{E}+05$ & 6.30 & 5.40 & 777 & 19 & 208 & 416 \\
\hline $\mathrm{EC}_{>12-16}$ & 200 & $7.60 \mathrm{E}-04$ & $4.90 \mathrm{E}+00$ & $1.29 \mathrm{E}+06$ & 7.90 & 6.70 & 802 & 13 & 208 & 416 \\
\hline $\mathrm{EC}_{>16-35}$ & 240 & $2.50 \mathrm{E}-06$ & 9.99E-02 & $1.22 \mathrm{E}+07$ & 10.40 & 8.80 & 838 & 10 & 340 & 681 \\
\hline \multicolumn{11}{|l|}{ Aromatic } \\
\hline $\mathrm{EC}_{5-7}$ & 78 & $1.77 \mathrm{E}+03$ & $6.39 \mathrm{E}+03$ & $4.44 \mathrm{E}+02$ & 2.13 & 2.13 & 884 & 209 & 900 & 1800 \\
\hline $\mathrm{EC}_{>7-8}$ & 92 & $5.35 \mathrm{E}+02$ & $1.78 \mathrm{E}+03$ & $5.38 \mathrm{E}+02$ & 2.65 & 2.25 & 871 & 43 & 360 & 720 \\
\hline $\mathrm{EC}_{>8-10}$ & 120 & $6.50 \mathrm{E}+01$ & $6.37 \mathrm{E}+02$ & $1.17 \mathrm{E}+03$ & 3.70 & 3.20 & 869 & 11 & 415 & 830 \\
\hline $\mathrm{EC}_{>10-12}$ & 130 & $2.50 \mathrm{E}+01$ & $6.37 \mathrm{E}+01$ & $3.47 \mathrm{E}+02$ & 3.90 & 3.40 & 885 & 10 & 552 & 1105 \\
\hline $\mathrm{EC}_{>12-16}$ & 150 & $5.80 \mathrm{E}+00$ & $4.90 \mathrm{E}+00$ & $1.32 \mathrm{E}+02$ & 4.30 & 3.70 & 941 & 5 & 436 & 871 \\
\hline $\mathrm{EC}_{>16-21}$ & 190 & $6.50 \mathrm{E}-01$ & $1.11 \mathrm{E}-01$ & $3.22 \mathrm{E}+01$ & 4.90 & 4.20 & 969 & 14 & 670 & 1340 \\
\hline $\mathrm{EC}_{>21-35}$ & 240 & $6.60 \mathrm{E}-03$ & $4.46 \mathrm{E}-05$ & $1.66 \mathrm{E}+00$ & 6.00 & 5.10 & 978 & 5 & 1440 & 2880 \\
\hline
\end{tabular}

${ }^{\text {a }}$ Henry's law constant for $\mathrm{EC}_{5-7}$ and $\mathrm{EC}>7-8$ aromatic fractions are quoted at $20^{\circ} \mathrm{C}$ (Nathanail et al., 2007)

${ }^{\mathrm{b}}$ density calculated using data from Røenningsen et al. (1989).

${ }^{c}$ Half-lives of each hydrocarbon fraction have been calculated as described in the compilation of property data for hydrocarbon fractions and indicators section 
Table 3: Physicochemical characteristics of the aromatic indicator compounds and their biodegradation half lives in air, water and bulk soil

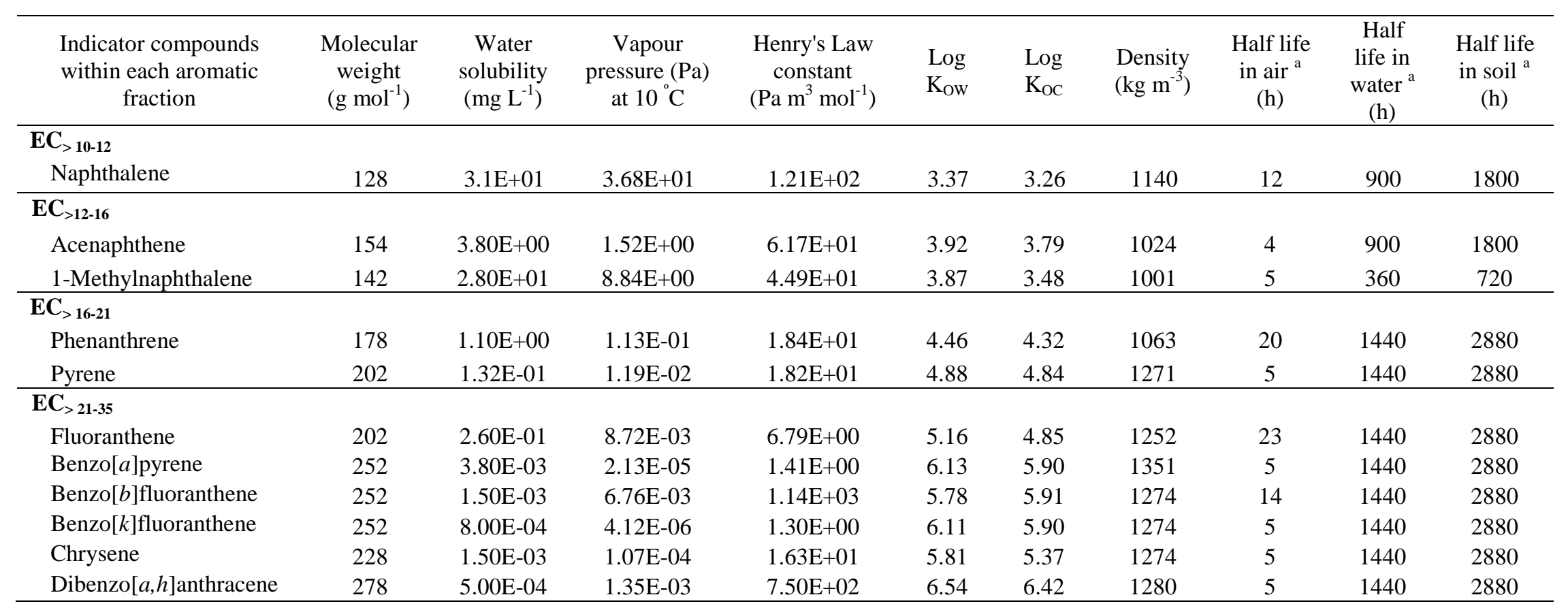

${ }^{\mathrm{a}}$ calculated using the Estimation Programs Interface (EPI) Suite ${ }^{\mathrm{TM}}$ for Microsoft ${ }^{\circledR}$ Windows, v3.20 (Syracuse Research Corporation) 


\section{Evaluating environmental fate of the hydrocarbon fractions within soil-oil matrix}

A bespoke multimedia fugacity model was constructed in order to predict the prevailing behaviour of the TPH fractions and indicator compounds within constructed biopile environments. Dynamic (time-explicit) predictions were made (Mackay, 2001), because steady state in the biopile is never achieved (i.e. chemical mass within the system is always changing as the soil is remediated). Each compound or fraction is characterised by its affinity for the compartment under consideration via the fugacity capacity or $Z$-value, which is a function of compartment composition and chemical-specific partition coefficients. The relationship between the fugacity and chemical concentration is given by:

$$
C=Z . f
$$

where $C$ is the concentration $\left(\mathrm{mol} \mathrm{m}^{-3}\right), f$ is the fugacity $(\mathrm{Pa})$ and $Z$ is the fugacity capacity which is the constant of proportionality, $\left(\mathrm{mol} \mathrm{m}^{-3} \mathrm{~Pa}^{-1}\right)$.

Individual Z- values were calculated for water, air, soil solids and NAPL using equations given in the Supporting Information. Although inter-compartmental transfers may limit the extent to which thermodynamic equilibrium can be achieved, such transfers are difficult to define within the biopile itself. The fugacity values of each compartment within the biopile were, therefore, assumed to be equal (i.e. equilibrium is achieved internally). A $Z$-value was derived for the bulk soil as the volume-fraction-weighted average of the individual compartment $Z$-values. This approach is in accordance with assumptions taken in other fugacity models developed for soil (Paterson et al., 1994; Di Guardo et al., 1994; McKone, 1996). At any time, $t$, the total amount of any single chemical contaminant inside the biopile, $M$ (mole), can be expressed as follows: 
where $f(\mathrm{~Pa})$ is the common fugacity of the contaminant fraction under consideration in the biopile, $Z_{B U L K}\left(\mathrm{~mol} \mathrm{~Pa}^{-1} \mathrm{~m}^{-3}\right)$ is the $Z$-value for the bulk soil and $V_{T}\left(\mathrm{~m}^{3}\right)$ is the total volume of the biopile.

Transport and transformation rate coefficients in fugacity models are represented as $D$-values $\left(\mathrm{mol} \mathrm{Pa}{ }^{-1} \mathrm{~h}^{-1}\right.$ ) which have the general form for reaction of $D=k \cdot V \cdot Z$ (where $k$ is the reaction rate constant $\left[\mathrm{h}^{-1}\right]$ and $V$ is volume $\left[\mathrm{m}^{3}\right]$ ) and for advection (e.g. leaching and air flow) of $D=$ $G . Z$ (where $G$ is the fluid flow rate $\left[\mathrm{m}^{3} \mathrm{~h}^{-1}\right]$ ). The $D$-values employed in the biopile model are given in the Supporting Information. Note that chemicals can be transported out of the biopile by three processes: (i) Diffusive transfer through the pore network followed by volatilisation to the surrounding air; (ii) Advective transfer of chemical in the air-filled pore space, as a consequence of air blown through the biopile and (iii) leaching (Mohn et al., 2001; Pollard et al., 2008). A steady-state water flow through the biopile was assumed at an arbitrary rate of $2.1 \times 10^{-3} \mathrm{~m}^{3} \mathrm{~h}^{-1}$ to allow for leaching losses occurring due to periodic wetting, which is employed to ensure optimal moisture content for biodegradation.

Biodegradation of the TPH fractions was assumed to occur according to first order kinetics in the bulk soil (not compartment-specific) and, independently, in the NAPL phase. It must be emphasized that the above model is a highly simplified representation of the abiotic and biotic processes occurring in a highly complex system. However, the assumptions are often tolerable, particularly in the absence of more detailed information such as the actual form of degradation kinetics taking place (Mackay, 2001). 
Chemical diffusion to the soil surface in the air-filled and water-filled pore space, and subsequent volatilization, was represented via two partial mass transfer coefficients acting in parallel (one for diffusion in air and one for diffusion in water) combined with a mass transfer coefficient in the overlying air film. The partial mass transfer coefficients in the soil were derived, in turn, from diffusion coefficients, modified for the tortuousity of the pore space according to the Millington-Quirk equation (Millington and Quirk, 1961). Further details are documented in Paterson et al. (1994), McKone (1996) and Mackay (2001). Since we assumed that there were no chemical inputs to the biopile, dynamic changes in fugacity $\left(f_{i}\right)$ for a given chemical fraction were calculated from:

$$
\frac{d f_{i}}{d t}=-\frac{D_{T_{i}} \cdot f_{i}}{V_{T} \cdot Z_{B U L K i}}
$$

where $t(\mathrm{~h})$ is time, $D_{T}\left(\mathrm{~mol} \mathrm{~Pa}{ }^{-1} \mathrm{~h}^{-1}\right)$ is the overall $D$-value (details provided in the Supporting Information). Equation (4) was solved numerically using Euler's method with a time step of 24 hours. Concentrations of each hydrocarbon fraction were derived from Equation (2).

The total concentration $\left(C_{T}, \mathrm{~mol} \mathrm{~m}{ }^{-3}\right)$ of all fractions in the bulk soil was also calculated at each time step as follows:

$$
C_{T}(t)=\sum_{i=1}^{N} C_{i}(t)
$$

where $C_{i}\left(\mathrm{~mol} \mathrm{~m}^{-3}\right)$ is the concentration of fraction $i$ and $N$ is the number of fractions considered. 


\section{Results and Discussion}

Equilibrium Mass Distributions The initial mass distributions of the hydrocarbon fractions among compartments for each biopile are shown in Figure 1. These distributions are effectively level I fugacity distributions (i.e. an equilibrium partitioning). They suggest that for many of the hydrocarbon fractions considered, the highest masses were predicted to reside in the NAPL and soil solid (soil organic matter) compartments. For Biopiles A and B, the NAPL was predicted to be the preferred compartment for all hydrocarbon fractions, with the exception of the $\mathrm{EC}_{5-7}$ aromatic fraction. In Biopile $\mathrm{C}$, which had a higher soil organic carbon content (13\%), soil organic matter was predicted to be the most important compartment for the light aliphatic fractions $\left(\mathrm{EC}_{5-6}\right.$ and $\left.\mathrm{EC}_{6-8}\right)$ and most of the aromatic fractions (with the exception of the $\mathrm{EC}_{16-21}$ and $\left.\mathrm{EC}_{21-35}\right)$.

Temporal Patterns The predicted temporal patterns of TPH concentration for all three biopile soils and all five scenarios are shown in Figure 2. The predictions were much more sensitive to whether or not degradation was assumed for the NAPL compartment than to whether or not an explicit NAPL compartment was included or not. Predictions were also sensitive to degradation rate in the NAPL phase between zero (Scenario 1) and the rate assumed for the bulk soil (Scenarios 2 and 3) due to the preference of many of the considered fractions for this phase. The predicted temporal change in TPH concentration for Scenarios 3 (NAPL - Deg), 4 (No NAPL - Enhanced SOC) and 5 (No NAPL) were very similar and the curves for each scenario were practically indistinguishable (Figure 2). This finding confirms the expectation that partitioning to the soil gas and water phases was relatively minor for the most prevalent hydrocarbon fractions (e.g. the aliphatic $\mathrm{EC}_{>12-16}$ and $\mathrm{EC}_{>16-35}$ and the aromatic $\mathrm{EC}_{>16-21}$ and $\mathrm{EC}_{>21-35}$ fractions) (Tabak et al., 1997; Foster et al., 2005). The fate of these fractions in Scenarios 3, 4 and 5 was determined almost exclusively by the rate of 

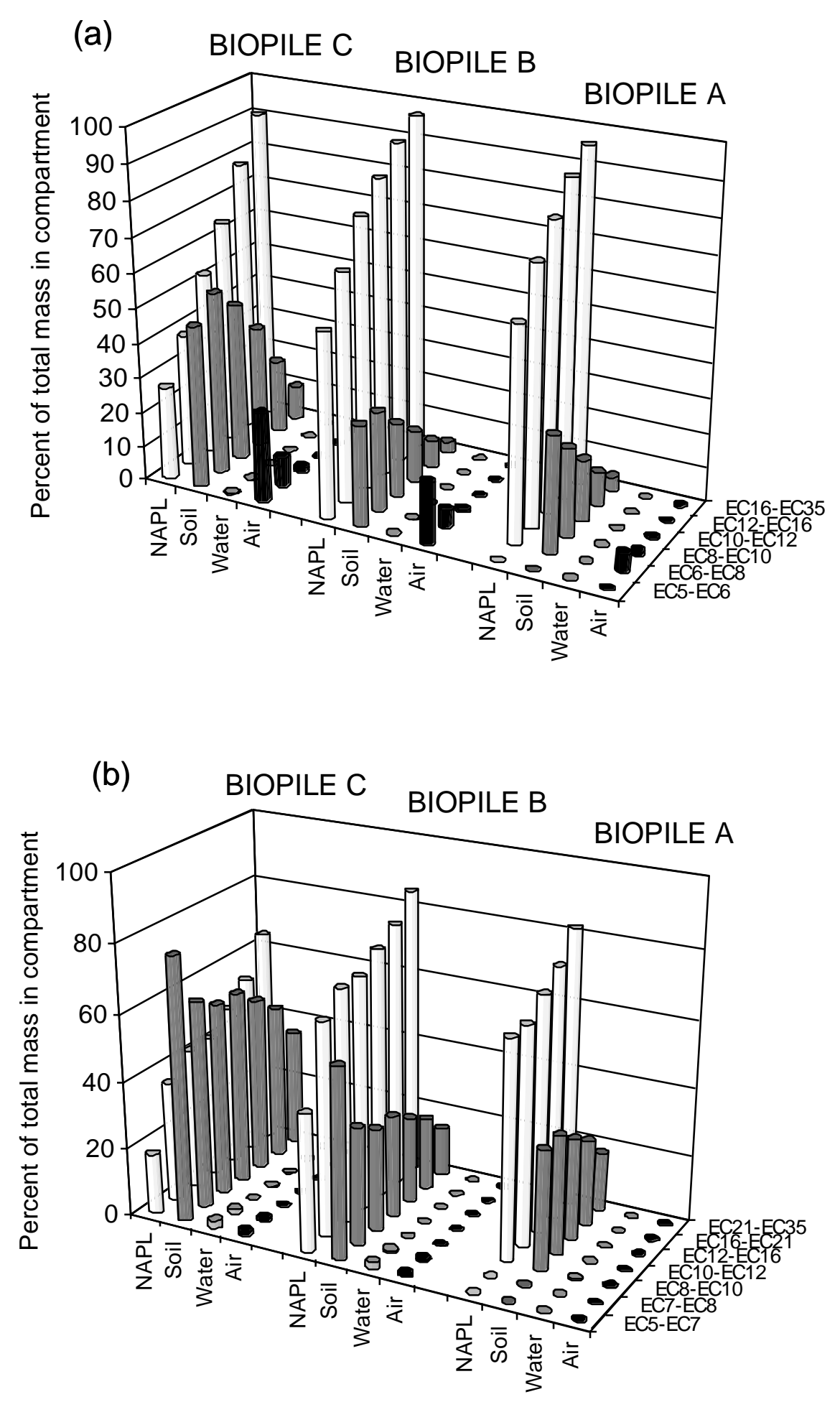

Figure 1: Estimated mass distribution of the petroleum hydrocarbon fractions among compartments in different biopiles, assuming the existence of an explicit NAPL compartment. (a) aliphatic compounds and (b) aromatic compounds. 
biodegradation which is assumed to proceed at the bulk soil rate. Changes in the lighter aliphatic fractions were, however, influenced by the inclusion of an explicit NAPL compartment in the model, resulting in a slower degradation rate (Figure 2d). This was due to reduced gas and water phase concentrations and associated leaching and (especially) volatilization. In any given scenario, the individual hydrocarbon fractions were predicted to dissipate from the biopile system at very different rates, driven by their physicochemical and degradation properties. The overall TPH loss patterns were closer to the "hockey stick" curve (Tabak et al., 1997) rather than being exponential. Thus, care must be taken in extrapolating overall TPH loss as TPH tends to become dominated by the slower dissipation rates of the more recalcitrant and less mobile fractions (McKone, 1996; Zemanek et al., 1997; Walter et al., 2000). This emphasises the importance of considering component fractions rather than TPH.

In Scenarios 3, 4 and 5, many of the modelled fractions were predicted to be effectively eliminated after 10 months (7632 hours) which is in the timescale of most biopiling operations ( 6 to 12 months) (Mohn et al., 2001; Pollard et al., 2008). With the exception of the aromatic $\mathrm{EC}_{>16-21}$ and $\mathrm{EC}_{>21-35}$ fractions and some of the PAH indicator compounds, most fractions in these scenarios had predicted concentrations at 10 months which were lower than $1 \%$ of their initial concentration. The most recalcitrant hydrocarbons were, as expected, the aromatic $\mathrm{EC}>21-35$ fraction and the heavier aromatic indicator compounds associated $(>15 \%$ remaining after 10 months) (Pollard et al., 1992; Zemanek et al., 1997). 

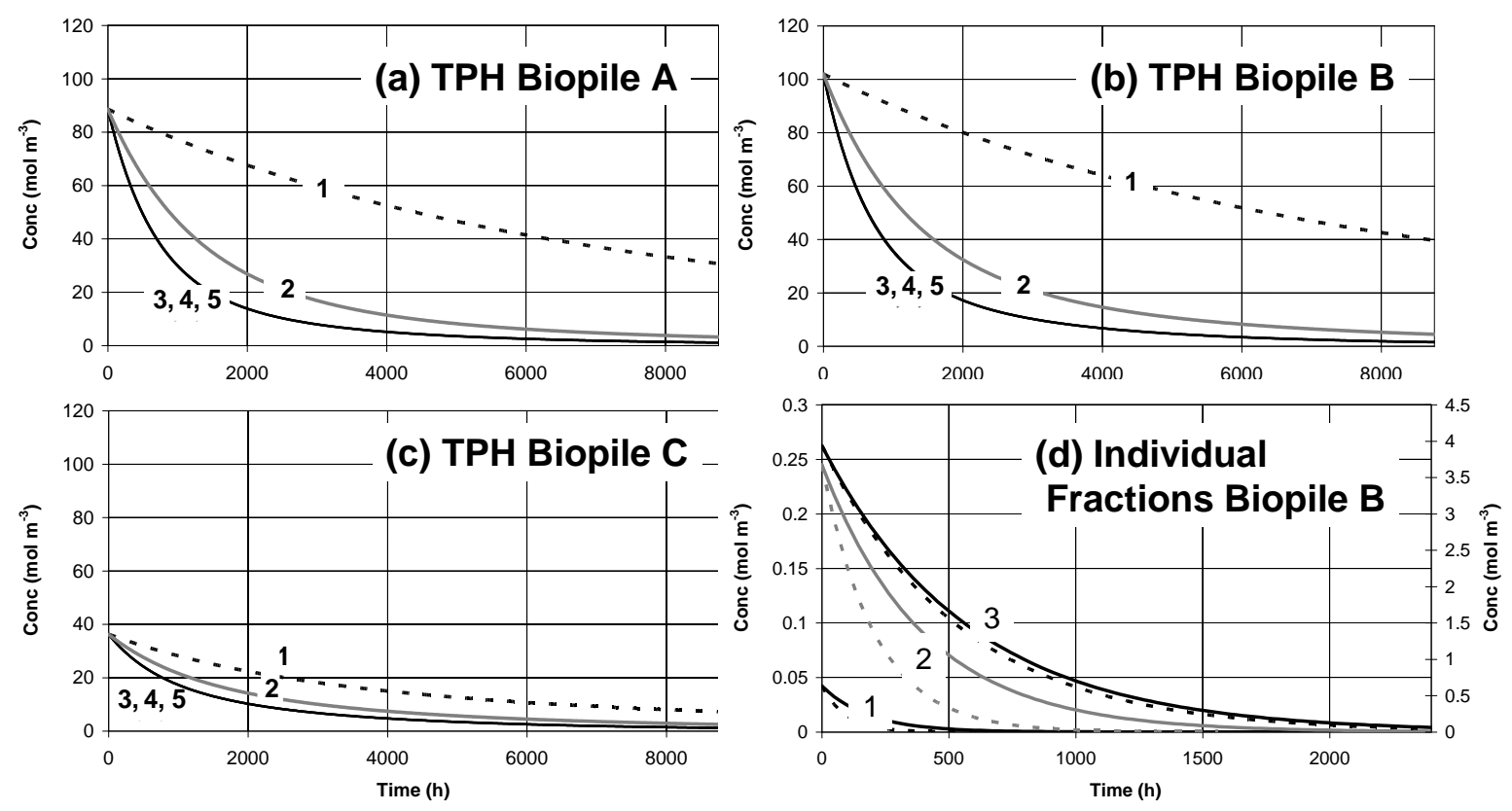

Figure 2: Predicted temporal change in TPH concentration in the three biopile soils $(\mathrm{a}, \mathrm{b}$ and c, respectively. Broken lines show results for Scenario 1 (NAPL - No deg), solid grey lines show results for Scenario 2 (NAPL - Deg half rate) and solid black lines show results for Scenarios 3 (NAPL-Deg), 4 (No NAPL - Enhanced SOC) and 5 (No NAPL), which are practically indistinguishable). Panel (d) illustrates the predicted concentrations of three individual aliphatic fractions in Biopile B with NAPL (Scenario 3: solid lines) and without NAPL (Scenario 5: dashed lines): $\left(1=\mathrm{EC}_{5-6} ; 2=\mathrm{EC}_{>6-8} ; 3=\mathrm{EC}_{>10-\mathrm{EC} 12}\right)$.

Comparison of predictions with measured concentrations The results obtained from the fugacity model for all five scenarios were compared with measured concentration data determined by GCMS after 6 months (180 days) of biopile treatment (Table 4$)$. For many of the hydrocarbon fractions, predicted concentrations were similar to those measured. Concentrations predicted by Scenario 1 (NAPL - No deg) significantly overestimated the measured concentrations for all hydrocarbon fractions on day 180 - sometimes by more than an order of magnitude. Predicted concentrations generated by Scenario 2 (NAPL - Deg half 
rate) also tended to overestimate the measured data. In contrast, concentrations (in all phases) predicted in Scenarios 3, 4 and 5 were often reasonably close to the observed concentrations, which is encouraging given the simple nature of the model and the assumptions made. Concentrations predicted for Scenario 3 (NAPL - Deg) tended to be slightly higher than those predicted for Scenarios 4 and 5. In the case of the aliphatic fractions, this was favourable with respect to the measured data but for the heavier aromatic fractions the model tended to slightly over predict measured concentrations. The quality of the match between the model prediction and the measured concentration for a given fraction or indicator compound is defined in Table 4 using the absolute error, expressed as a percentage of the measured concentration. For most hydrocarbon fractions and for most aromatic indicator compounds the predicted concentrations from Scenarios 3-5 were within a factor 3 of measured concentrations (absolute error $<67 \%$ ) and often much closer. This indicates that the inclusion of an explicit NAPL, as initially postulated, was not, after all, essential for modelling the behaviour of many hydrocarbon fractions. On the other hand, differences in the predicted behaviour of the lighter fractions with and without a NAPL (Figure 2d) suggest that, for better prediction of hydrocarbon mobility, it may still be advantageous to include the NAPL with an assumption that the degradation rate in this phase is similar to that in the bulk soil.

Importance of Different Loss Processes The predicted contribution of different processes (leaching, loss in advected air, degradation in the bulk soil, degradation in the NAPL and 
Table 4 Comparison of measured and predicted concentrations $(C)$ of the hydrocarbon fractions and the risk indicator compounds in the soil phase after 180 days of treatment in Biopile B. Scenario 1 assumes an explicit NAPL compartment with no degradation in the NAPL; Scenario 2 assumes an explicit NAPL compartment with the degradation rate in the NAPL = half that in the bulk soil; Scenario 3 assumes an explicit NAPL compartment with degradation in the NAPL = degradation in the bulk soil; Scenario 4 assumes no explicit NAPL compartment but SOM content is enhanced by the presence of oil residues and Scenario 5 makes no allowance for the oil phase whatsoever.

\begin{tabular}{|c|c|c|c|c|c|c|c|}
\hline Aliphatic (mg kg $\left.{ }^{-1}\right)$ & $\begin{array}{c}C_{O} \\
\text { measured }^{\text {a }}\end{array}$ & $\begin{array}{c}C_{180 \text { days }} \\
\text { measured }^{\mathrm{a}}\end{array}$ & $\begin{array}{l}C_{180 \text { days }} \\
\text { predicted }^{\mathrm{b}} \\
\text { Scenario } 1\end{array}$ & $\begin{array}{l}C_{180 \text { days }} \\
\text { predicted } \\
\text { Scenario } 2\end{array}$ & $\begin{array}{c}C_{180 \text { days }} \\
\text { predicted } \\
\text { Scenario } 3\end{array}$ & $\begin{array}{c}C_{180 \text { days }} \\
\text { predicted } \\
\text { Scenario } 4\end{array}$ & $\begin{array}{c}C_{180 \text { days }} \\
\text { predicted } \\
\text { Scenario } 5\end{array}$ \\
\hline $\mathrm{EC}_{5-6}$ & $5(2)$ & - & $<0.01(-)$ & $<0.01(-)$ & $<0.01(-)$ & $<0.01(-)$ & $<0.01(-)$ \\
\hline $\mathrm{EC}_{>6-8}$ & $36(14)$ & $<4(0.5)$ & $0.04(<99)$ & $0.01(<100)$ & $<0.01(<100)$ & $<0.01 \quad(<100)$ & $<0.01 \quad(<100)$ \\
\hline $\mathrm{EC}_{>8-10}$ & $50(22)$ & $<4(0.5)$ & $5(26)$ & $0.31(<92)$ & $0.02(<100)$ & $<0.01(<100)$ & $<0.01(<100)$ \\
\hline $\mathrm{EC}_{>10-12}$ & $915(86)$ & $50(4)$ & $282(464)$ & $12(75)$ & $0.5(99)$ & $0.4(99)$ & $0.3(99)$ \\
\hline $\mathrm{EC}_{>12-16}$ & $14608(1102)$ & $28(3)$ & 8069 (28718) & $277(891)$ & $9(68)$ & $8(71)$ & $8(72)$ \\
\hline $\mathrm{EC}_{>16-35}$ & $4256(209)$ & $65(5)$ & 3667 (5542) & $426(556)$ & $48(26)$ & $48(26)$ & $48(26)$ \\
\hline Total & $19869(1235)$ & $151(12)$ & $12025(7864)$ & $716(374)$ & $58(62)$ & $57(62)$ & $56(63)$ \\
\hline \multicolumn{8}{|l|}{ Aromatic $\left(\mathrm{mg} \mathrm{kg}^{-1}\right)$} \\
\hline $\mathrm{EC}_{5-7}$ & $1(0.5)$ & - & $0.17(-)$ & $0.12(-)$ & $0.08(-)$ & $0.07(-)$ & $0.04(-)$ \\
\hline $\mathrm{EC}_{>7-8}$ & $6(3)$ & $<4(0.5)$ & $0.7(83)$ & $0.18(95)$ & $0.05(99)$ & $0.03(99)$ & $0.02(100)$ \\
\hline $\mathrm{EC}_{>8-10}$ & $23(9)$ & $<4(0.5)$ & 7 (66) & $1.86(53)$ & $0.5(87)$ & $0.4(99)$ & $0.4(90)$ \\
\hline $\mathrm{EC}_{>10-12}$ & $86(25)$ & $<4(0.5)$ & $9(138)$ & $0.77(81)$ & $0.06(99)$ & $0.06(99)$ & $0.06(99)$ \\
\hline $\mathrm{EC}_{>12-16}$ & $1599(161)$ & $60(8)$ & $652(987)$ & 179 (198) & 49 (18) & $48(20)$ & $48(20)$ \\
\hline $\mathrm{EC}_{>16-21}$ & $4275(350)$ & 387 (39) & $2627(579)$ & $1084(180)$ & $446(15)$ & $445(15)$ & $445(15)$ \\
\hline $\mathrm{EC}_{>21-35}$ & $3697(318)$ & $1160(98)$ & $3166(173)$ & $2026(75)$ & $1296(12)$ & $1296(12)$ & $1296(12)$ \\
\hline Total & $9686(529)$ & $1619(110)$ & $6462(299)$ & $3292(103)$ & $1790(11)$ & $1790(11)$ & $1789(11)$ \\
\hline \multicolumn{8}{|c|}{ PAH indicator compounds $\left(\mathrm{mg} \mathrm{kg}^{-1}\right)$} \\
\hline Naphthalene & $43(4)$ & - & $19(-)$ & $12(-)$ & $8(-)$ & $8(-)$ & $8(-)$ \\
\hline Acenaphthene & $24(3)$ & - & $4(-)$ & $1.1(-)$ & $0.4(-)$ & $0.4(-)$ & $0.4(-)$ \\
\hline 1-methylnaphthalene & $36(3)$ & $<4(0.5)$ & $2(<45)$ & $1.0(76)$ & $0.4(89)$ & $0.4(90)$ & $0.4(91)$ \\
\hline Phenanthrene & $64(8)$ & $9(3)$ & $43(378)$ & $31(247)$ & $23(156)$ & $22(150)$ & $22(150)$ \\
\hline Pyrene & $12(2)$ & $5(2)$ & $8(60)$ & $6(17)$ & $4(14)$ & $4(14)$ & $4(14)$ \\
\hline Fluoranthene & $13(2)$ & $3(1)$ & $8(180)$ & $6(104)$ & $5(50)$ & $5(50)$ & $5(50)$ \\
\hline Benzo $[a]$ pyrene & $9(1)$ & $8(3)$ & $4(55)$ & $3(58)$ & $3(61)$ & $3(61)$ & $3(61)$ \\
\hline Benzo $[b]$ fluoranthene & $7(1)$ & $6(2)$ & $6(5)$ & $4(39)$ & $2(60)$ & $2(60)$ & $2(60)$ \\
\hline Benzo $[k]$ fluoranthene & $7(1)$ & $7(2)$ & $5(36)$ & $3(53)$ & $2(66)$ & $2(66)$ & $2(66)$ \\
\hline Chrysene & $5(1)$ & $5(2)$ & $3(32)$ & $3(50)$ & $2(64)$ & $2(64)$ & $2(64)$ \\
\hline Dibenzo $[a, h]$ anthracene & $4(1)$ & $4(2)$ & $3(33)$ & $2(51)$ & $1(65)$ & $1(65)$ & $1(65)$ \\
\hline
\end{tabular}

“_..Peaks not identified by GC-MS; ${ }^{a}$ Each value represents the mean amount from duplicate samples and the standard error is shown in parentheses. ${ }^{\mathrm{b}}$ Absolute concentration error expressed as a percentage of the measured concentration shown in parentheses 
diffusive volatilisation) to the overall loss of the individual hydrocarbon fractions is shown in Table 5 for Biopile B, Scenario 3 (NAPL - Deg) for which predicted concentrations were generally closest to the measured values. It is clear that for the lighter fractions, particularly the aliphatic fractions (which have relatively high $\mathrm{K}_{A W}$ ), loss to the air by advection and volatilisation is significant. In the case of the aliphatic $\mathrm{EC}_{5-6}, \mathrm{EC}_{>6-8}$ and aromatic $\mathrm{EC}_{5-7}$ fractions these processes were responsible for over $35 \%$ of total losses. This finding has been also reported by Foster et al. (2005), who investigated environmental exposure to a mixture of gasoline products. The predicted air phase concentrations of these fractions, which included toxic compounds such as benzene $\left(57 \mathrm{mg} \mathrm{m}^{-3}\right)$ and toluene $\left(600 \mathrm{mg} \mathrm{m}^{-3}\right)$, were relatively high (Coulon et al., 2009) and may contribute to the commonly occurring odour events at biopiling sites. The air phase fluxes of risk-critical contaminants warrants further examination. In contrast, soil-air transfer was relatively unimportant for the heavier fractions, for which degradation was more important. For all fractions with ECn $>8$, degradation accounted for $\geq 90 \%$ of total losses. However, it should be emphasised that the absolute overall loss rate decreased with increasing molar mass (as indicated by an increase in the effective median dissipation time [DT50]). Leaching was not predicted to be a significant loss mechanism in terms of affecting overall soil concentrations for any of the fractions examined and never exceeded $0.01 \%$ of the total loss for any fraction. However, this was not to say that leaching will always be unimportant from an environmental contamination perspective (Tabak et al., 1997; Park and Juan, 2000). Concentrations in pore water were predicted to be relatively high for some fractions. For example, the highest concentrations predicted in the pore water of Biopile B after 180 days were 111 and $499 \mu \mathrm{g} \mathrm{L}^{-1}$ for the aromatic EC $>16-21$ fraction in Scenarios 3 (NAPL - Deg) and 5 (No NAPL), respectively (data not shown). For most fractions pore water concentrations were significantly reduced by including a NAPL phase. For example in Biopile B, aqueous concentrations of the different fractions considered were on average 3.8 times higher in Scenario 5, when NAPL was ignored completely, compared with Scenario 3 (NAPL - Deg). Predicted leaching was consequently always reduced by the presence of 
Table 5: Predicted contribution of different processes and median dissipation half-lives $\left(\mathrm{DT}_{50}\right)$ for representative hydrocarbon fractions and indicator compounds in Biopile B for Scenario 3 (NAPL - Deg)

\begin{tabular}{|c|c|c|c|c|c|c|}
\hline $\begin{array}{l}\text { Hydrocarbon fractions and } \\
\text { indicators }\end{array}$ & $\begin{array}{l}\% \text { loss by } \\
\text { leaching }\end{array}$ & $\begin{array}{c}\% \text { loss by } \\
\text { advection in } \\
\text { air }\end{array}$ & $\begin{array}{c}\% \text { loss by } \\
\text { degradation in } \\
\text { bulk soil }\end{array}$ & $\begin{array}{c}\% \text { loss by } \\
\text { degradation in } \\
\text { NAPL }\end{array}$ & $\begin{array}{l}\% \text { loss by } \\
\text { volatilization }\end{array}$ & $\begin{array}{r}\mathrm{DT}_{50} \\
\text { (days) }\end{array}$ \\
\hline \multicolumn{7}{|l|}{ Aliphatic } \\
\hline $\mathrm{EC}_{5-6}$ & $<0.01$ & 64 & 13 & 14 & 9 & 6 \\
\hline $\mathrm{EC}_{>6-8}$ & $<0.01$ & 40 & 19 & 36 & 6 & 12 \\
\hline $\mathrm{EC}_{>8-10}$ & $<0.01$ & 8 & 20 & 71 & 1 & 16 \\
\hline $\mathrm{EC}_{>10-12}$ & $<0.01$ & 1 & 15 & 84 & 0.1 & 17 \\
\hline $\mathrm{EC}_{>12-16}$ & $<0.01$ & 0.1 & 8 & 92 & 0.02 & 17 \\
\hline $\mathrm{EC}_{>16-35}$ & $<0.01$ & 0.01 & 3 & 97 & $<0.01$ & 29 \\
\hline \multicolumn{7}{|l|}{ Aromatic } \\
\hline $\mathrm{EC}_{5-7}$ & $<0.01$ & 32 & 37 & 26 & 5 & 47 \\
\hline $\mathrm{EC}_{>7-8}$ & $<0.01$ & 10 & 32 & 56 & 2 & 27 \\
\hline $\mathrm{EC}_{>8-10}$ & $<0.01$ & 3 & 30 & 67 & 0.4 & 34 \\
\hline $\mathrm{EC}_{>10-12}$ & $<0.01$ & 0.3 & 30 & 69 & 0.04 & 18 \\
\hline $\mathrm{EC}_{>12-16}$ & $<0.01$ & 0.1 & 26 & 74 & 0.01 & 36 \\
\hline $\mathrm{EC}_{>16-21}$ & $<0.01$ & 0.01 & 22 & 78 & $<0.01$ & 56 \\
\hline $\mathrm{EC}_{>21-35}$ & $<0.01$ & $<0.01$ & 15 & 85 & $<0.01$ & 120 \\
\hline \multicolumn{7}{|l|}{ Indicator compounds } \\
\hline Naphthalene & $<0.01$ & 1 & 47 & 52 & 0.2 & 74 \\
\hline Acenaphthene & $<0.01$ & 0.1 & 45 & 54 & 0.02 & 30 \\
\hline 1-methylnaphthalene & $<0.01$ & 4 & 59 & 36 & 1 & 29 \\
\hline Phenanthrene & $<0.01$ & 0.01 & 38 & 62 & $<0.01$ & 120 \\
\hline Pyrene & $<0.01$ & $<0.01$ & 41 & 59 & $<0.01$ & 120 \\
\hline Fluoranthene & $<0.01$ & $<0.01$ & 40 & 60 & $<0.01$ & 120 \\
\hline Benzo $[a]$ pyrene & $<0.01$ & $<0.01$ & 87 & 13 & $<0.01$ & 120 \\
\hline Benzo $[b]$ fluoranthene & $<0.01$ & $<0.01$ & 17 & 83 & $<0.01$ & 120 \\
\hline Benzo $[k]$ fluoranthene & $<0.01$ & $<0.01$ & 40 & 60 & $<0.01$ & 120 \\
\hline Chrysene & $<0.01$ & $<0.01$ & 40 & 60 & $<0.01$ & 120 \\
\hline Dibenzo $[a, h]$ anthracene & $<0.01$ & $<0.01$ & 42 & 58 & $<0.01$ & 120 \\
\hline
\end{tabular}


NAPL by at least $14 \%$ in the case of the lighter aliphatic fractions but by as much as $97 \%$ in the case of the heavier aliphatic fractions.

Comparison of the dissipation half-lives for the hydrocarbon fractions and their respective indicator compounds (e.g. compare the $\mathrm{DT}_{50} \mathrm{~s}$ for $\mathrm{EC}_{10-12}$ and naphthalene) showed a difference of up to 3 months (Table 5). This finding suggests that the potential for variability and inherent uncertainty is high when evaluating chemical mixtures using the properties of a single compound within a multimedia model (Park and Juan, 2000; Nathanail et al., 2007). It should be remembered that the values shown here represent only a small component of the total number of compounds in each fraction.

\section{Conclusions}

Overall, it appears that models of this kind provide useful tools for estimating the environmental fate of hydrocarbons in soils and in biopile systems, in particular, although more validation is required for a range of substances with differing physicochemical properties, reactivity and transport characteristics. The favourable (albeit limited) concentration comparisons shown in Table 4 also suggest that EPI-estimated degradation rates are appropriate for use in models of this kind. Unfortunately we did not measure hydrocarbon concentrations in the mobile biopile phases (water and air), which would have been useful for validating model predictions of advective fluxes. Future studies of contaminant behaviour in biopiles should look at these phases explicitly in order to get quantitative empirical estimates of the importance of different fate pathways. The detailed evaluation of different fractions could facilitate the implementation of effective remediation at contaminated sites and help the appraisal of residual petroleum hydrocarbon levels that can be left at remediated sites without posing unacceptable risk. 
Further research on the bioavailability of hydrocarbon fractions and their rate of biodegradation in the NAPL is still needed to better predict when end-point remediation will be reached which, in turn, will reduce the decision times as well as reducing the costs for chemical analysis.

Acknowledgements This work was supported by the LINK Bioremediation Programme (BIOREM_35) and funded by the UK Department for Business Innovation and Skills (BIS), the Environment Agency of England and Wales (EA) and the Biotechnology and Biological Sciences Research Council BBSRC (Grant BB/B512432/1). We thank Prof. Phil Howard for his useful comments and for supplying additional information about transformation rates of the petroleum hydrocarbon fractions. We are also grateful to two anonymous referees for their insightful comments and suggestions.

\section{Supporting Information Available}

The subset of representative chemicals in crude oil component groups for which property data and degradation half-lives in relevant media were selected is given in supporting tables. Definitions of $\mathrm{Z}$ and $\mathrm{D}$ values are also provided. This material is available free of charge via the Internet at http://www.sciencedirect.com. 


\section{Literature Cited}

Battelle, 1996.Biopile design and construction manual.Technical Memorandum TM-2189ENV for Naval Facilities Engineering Service Center (NFESC), Port Hueneme, California, USA.

Brassington, K.J., Hough, R.L., Paton, G.I., Semple, K.T., Risdon, G.C., Crossley, J., Hay, I., Askari, K., Pollard, S.J.T., 2007. Weathered hydrocarbon wastes: A risk management primer. Crit. Rev. Environ. Sci. Technol. 37, 199-232.

Brown, D.G., Knightes, C.D., Peters, C.A., 1999. Risk assessment for polycyclic aromatic hydrocarbon NAPLs using component fractions. Environ. Sci. Technol. 33, 4357-4363.

Coulon, F., Orsi, R., Turner, C., Walton, C., Daly, P., Pollard, S.J.T., 2009. Understanding the fate and transport of petroleum hydrocarbons from coal tar within gasholders. Environ. Int. $35,248-252$.

Di Guardo, A., Calamari, D., Zanin, G., Consalter, A. Mackay, D., 1994. A fugacity model of pesticide runoff to surface water: Development and validation. Chemosphere 28, 511-531.

Farrell-Jones, J., 2003. Petroleum hydrocarbons and polyaromatic hydrocarbons. In chemical analysis of contaminated land; Thompson, C.K., Nathanail, P. C., eds.; Blackwell, Oxford, pp 132-176.

Foster, K.L., Mackay, D., Parkerton, T.F., Webster, E., Milford, L., 2005. Five-stage environmental exposure assessment strategy for mixtures: gasoline as a case study. Environ. Sci. Technol. 39, 2711-2718. 
Howard, P., Meylan, W., Aronson, D., Stiteler, W., Tunkel, J., Comber, M., Parkerton, T.F., 2005.A new biodegradation prediction model specific to petroleum hydrocarbons. Environ. Toxicol. Chem. 24, 1847-1860.

Huesemann, M.H., Hausmann, T.S., Fortman, T.J., 2004. Does bioavailability limit biodegradation? A comparison of hydrocarbon biodegradation and desorption rates in aged soils. Biodegradation 15, 261-274.

Mackay, D., Paterson, S., 1991. Evaluating the multimedia fate of organic chemicals: A level III fugacity model. Environ. Sci. Technol. 25, 427-436.

Mackay, D., 2001. Multimedia environmental models: the fugacity approach, $2^{\text {nd }}$ edition, Lewis Publishers, MI.

McKone, T.E., 1996. Alternative modeling approaches for contaminant fate in soils: uncertainty, variability and reliability. Reliab. Eng. Syst. Saf. 54, 165-181.

Millington, R.J., Quirk, J.M., 1961. Permeability of porous solids. Transactions of the Faraday Society. 57, 1200-1207.

Mohn, W.W., Radziminski, C.Z., Fortin, M., Reimer, K.J., 2001.On site bioremediation of hydrocarbon-contaminated Arctic tundra soils in inoculated biopiles. Appl. Microbiol. Biot. $57,242-247$.

Nathanail, C.P., McCaffrey, C., Ashmore, M.; Cheng, Y., Gillet, A., Hooker, P., Ogden, R.C., 2007. Generic Assessment criteria for human health risk assessment. Land Quality Press, Nottingham. ISN 0-9547474-3-7.

Paterson, S., Mackay, D., McFarlane C., 1994.A model of organic chemical uptake by plants from soil and the atmosphere. Environ. Sci. Technol. 28, 2259-2266. 
Pollard, S.J.T., Hrudey, S.E., Fuhr, B.J., Alex, R.F., Holloway, L.R. and Tosto, F., 1992.

Hydrocarbon wastes at petroleum and creosote-contaminated sites: rapid characterisation of class components by thin layer chromatography with flame ionization detection. Environ. Sci. Technol. 26, 2528-2534

Pollard, S.J.T., Hrudey, S.E., Fedorak, P.M., 1994. Bioremediation of petroleum- and creosote-contaminated soils: A review of constraints. Waste Manage. Res. 12, 173-194.

Pollard, S.J.T., Hough, R.L., Kim, K.-H., Bellarby, J., Paton, G., Semple, K.T., Coulon, F., 2008. Fugacity modelling to predict the distribution of organic contaminants in the soil:oil matrix of constructed biopiles. Chemosphere 71, 1432-1439.

Risdon, G.C., Pollard, S.J.T., Brassington, K.J., McEwan, J.N., Paton, G.I., Semple, K.T., Coulon, F., 2008. Development of an analytical procedure for weathered hydrocarbon contaminated soils within a UK risk-based framework. Anal.Chem. 80, 7090-7096.

Røenningsen, H.P.,Skjevrak, I.,Osjord, E., 1989. Characterization of North Sea petroleum fractions: hydrocarbon group types, density and molecular weight. Energy Fuels 3, 744-755.

Semple, K.T., Morris, A.W.J., Paton, G.I., 2003. Bioavailability of hydrophobic organic contaminants in soils: Fundamental concepts and techniques for analysis. European J. Soil Sci. 54, 809-818.

Tabak, H.H., Govind, R., 1997. Protocol for determining bioavailability and biokinetics oforganic pollutants in dispersed, compacted and intact soil systems to enhance in situ bioremediation. J. Ind. Microbiol. Biotechnol. 18, 330-339. 
TPHCWG, 1999. Total Petroleum Hydrocarbon Working Group Series Volume 5: Human health risk-based evaluation of petroleum release sites: implementing the working group approach. Amherst Scientific, Amherst, Massachusetts.

Twerdok, L.E., 1999. Development of Toxicity Criteria for Petroleum Hydrocarbon Fractions in the Petroleum Hydrocarbon Criteria Working Group Approach for Risk-Based Management of Total Petroleum Hydrocarbons in Soil. Drug Chem. Toxicol. 22, 275-291.

Walter, T., Ederer, H.J., Först, C., Stieglitz, L., 2000. Sorption of selected polycyclic aromatic hydrocarbons on soils in oil- contaminated systems. Chemosphere 41, 387-397.

Weisman, W.H., 1998. Total petroleum hydrocarbon criteria working group: a risk-based approach for the management of total petroleum hydrocarbons in soil. J. Soil Contam. 7, 115.

Zemanek, M.G., Pollard, S.J.T., Kenefick, S.L., Hrudey, S.E., 1997. Multi-phase partitioning and co-solvent effects for polynuclear aromatic hydrocarbons (PAH) in authentic petroleumand creosote-contaminated soils. Environ. Pollut. 98, 239-252 